
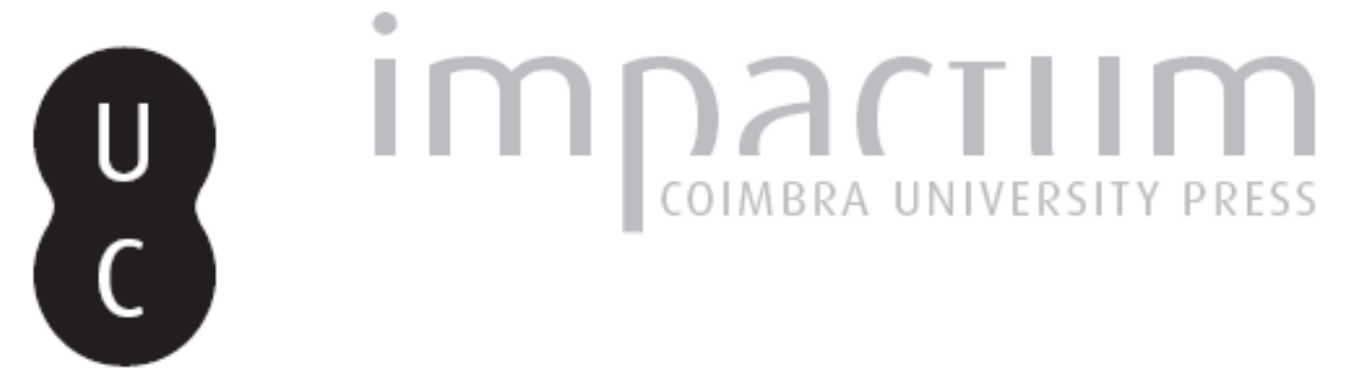

\title{
A tempestade de 23 de dezembro de 2009: causas meteorológicas e impactes na região Oeste de Portugal Continental
}

\author{
Autor(es): $\quad$ Lopes, António; Fragoso, Marcelo \\ Publicado por: Associação Portuguesa de Riscos, Prevenção e Segurança \\ URL \\ persistente: \\ URl:http://hdl.handle.net/10316.2/35856 \\ DOI: \\ DOI:http://dx.doi.org/10.14195/1647-7723_19_3 \\ Accessed : $\quad$ 26-Apr-2023 11:03:23
}

A navegação consulta e descarregamento dos títulos inseridos nas Bibliotecas Digitais UC Digitalis, UC Pombalina e UC Impactum, pressupõem a aceitação plena e sem reservas dos Termos e Condições de Uso destas Bibliotecas Digitais, disponíveis em https://digitalis.uc.pt/pt-pt/termos.

Conforme exposto nos referidos Termos e Condições de Uso, o descarregamento de títulos de acesso restrito requer uma licença válida de autorização devendo o utilizador aceder ao(s) documento(s) a partir de um endereço de IP da instituição detentora da supramencionada licença.

Ao utilizador é apenas permitido o descarregamento para uso pessoal, pelo que o emprego do(s) título(s) descarregado(s) para outro fim, designadamente comercial, carece de autorização do respetivo autor ou editor da obra.

Na medida em que todas as obras da UC Digitalis se encontram protegidas pelo Código do Direito de Autor e Direitos Conexos e demais legislação aplicável, toda a cópia, parcial ou total, deste documento, nos casos em que é legalmente admitida, deverá conter ou fazer-se acompanhar por este aviso.

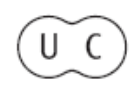




\section{territorium}

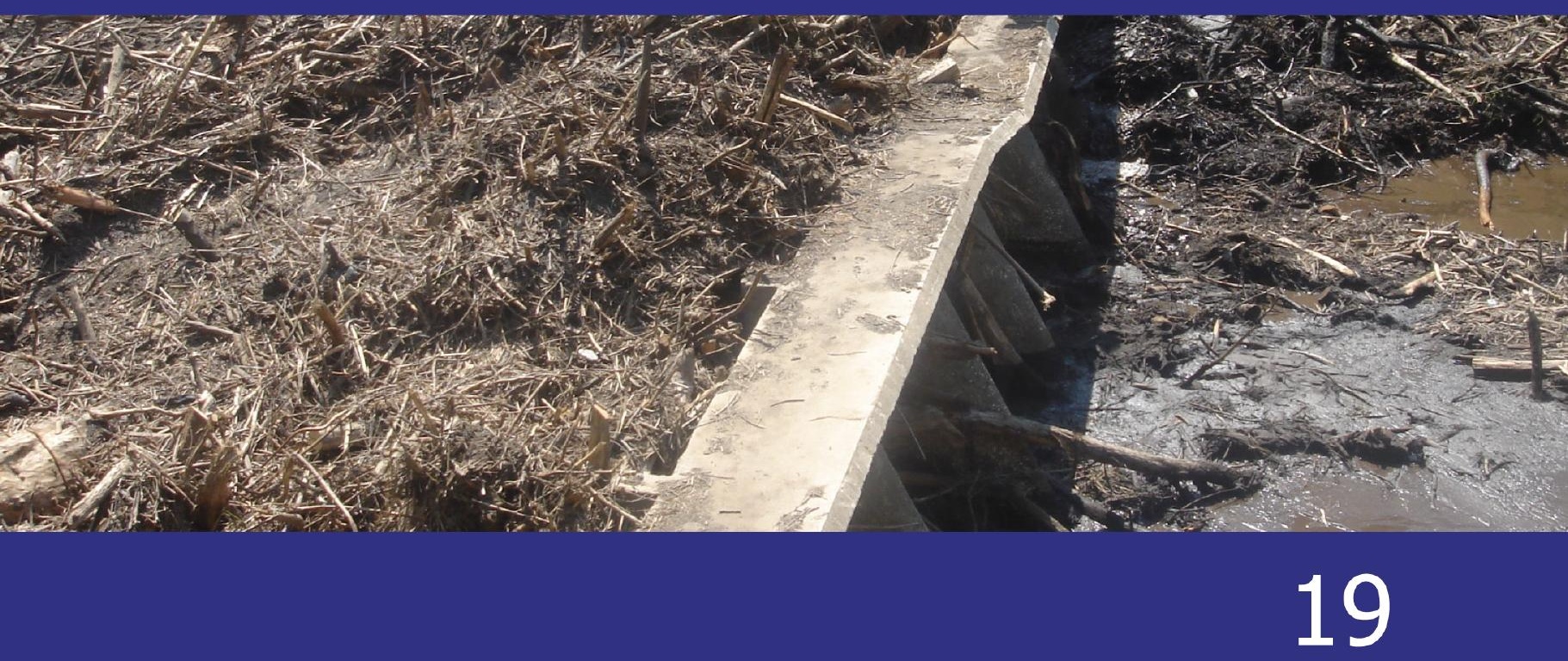

\section{Reequacionar o Conhecimento dos Riscos e das Catástrofes}

Revista da Associação Portuguesa de Riscos, Prevenção e Segurança 

PORTUGAL CONTINENTAL*

António Lopes
CEG, Instituto de Geografia e Ordenamento do Território da Universidade de Lisboa antonio.lopes@campus.ul.pt

Marcelo Fragoso

CEG, Instituto de Geografia e Ordenamento do Território da Universidade de Lisboa mfragoso@campus.ul.pt

\section{RESUMO}

No dia 23 de Dezembro de 2009 a região Oeste foi atingida por uma tempestade extratropical com ventos muito fortes (as rajadas foram superiores a $140 \mathrm{~km} / \mathrm{h}$ ), que derrubaram torres de alta tensão (provocando cortes no abastecimento de energia) e árvores. As consequências mais gravosas ocorreram nos distritos de Lisboa, Leiria e Santarém. As quedas de árvores constituíram a maior parte das ocorrências observadas, sendo por isso necessário e urgente proceder-se à realização de inventários sobre o estado fitossanitário das árvores em ambiente urbano.

Palavras chave: Tempestade de vento, ciclogénese rápida, impactos, queda de árvores.

\section{RESUMEN}

La tempestad del 23 deciembre 2009: causas meteorológicas e impactos en la región oeste de Portugal - El 23 de diciembre de 2009, la región occidental de Portugal fue alcanzada por una tormenta extratropical con vientos muy fuertes (ráfagas superiores a $140 \mathrm{~km} / \mathrm{h}$ ), que derribó torres de alta tensión y árboles. Las consecuencias más graves se produjeron en los distritos de Lisboa, Leiria y Santarém. Los árboles caídos fueron los casos más observados y por ello surge una fuerte necesidad de realizar unos inventários sobre el estado fito-sanitario de los árboles en el medio urbano. Palabras clave: Tormenta de viento, ciclogénesis rápida, impactos, árboles caidos.

\section{RÉSUMÉ}

La tempête du 23 décembre 2009: causes météorologiques et incidences dans l'Ouest du Portugal - Le 23 Décembre 2009, la région de l'ouest du Portugal a été touché par une tempête associée à une cyclogenèse rapide, et qui a causé forts vents à la surface, avec des rafales supérieures à $140 \mathrm{~km} / \mathrm{h}$. Les effets des vents violents ont été ressentis dans le renversement des tours de haute tension et également dans la chute d'arbres qui ont constitué la grande majorité des événements. Il est donc nécessaire préparer d'inventaires sur la situation phytosanitaire des forêts urbaines.

Mots-clé: Tempêtes, cyclogenèse rapide, incidences, chute d'arbres.

\section{ABSTRACT}

The 23rd December 2009 windstorm. Meteorological causes and impacts in the western region of Portugal - On this date the Portuguese region of "Oeste" (Estremadura and western Ribatejo) was hit by an extreme extratropical windstorm with gusts greater than $140 \mathrm{~km} / \mathrm{h}$. The overwhelming effects of such violent winds have severe impacts on high-power lines. Trees were uprooted all over the region and greenhouses with horticultures were very damaged or destroyed. Therefore the implementation of a survey about the fitossanitary conditions of trees in urban areas is necessary.

Key words: Windstorm; rapid cyclogenesis; impacts; falling trees; Lisbon Region.

\footnotetext{
* O texto deste artigo corresponde à comunicação apresentada ao II Congresso Internacional de Riscos e VI Encontro Nacional, tendo sido submetido para revisão em 02-08-2010, tendo sido aceite para publicação em 30-10-2010.

Este artigo é parte integrante da Revista Territorium, n. ${ }^{\circ} 19,2012,{ }^{\circ}$ RIscos, ISBN: 0872- 8941.
} 


\section{Introdução}

As tempestades são fenómenos meteorológicos extremos, gerados em sistemas de baixas pressões - no nosso domínio geográfico, ciclones extratropicais intensos - que produzem uma vasta zona de ventos violentos à superfície e cujas rajadas podem superar geralmente $120 \mathrm{~km} / \mathrm{h}$ nas regiões costeiras e $100 \mathrm{~km} / \mathrm{h}$ nas regiões interiores. Os factores meteorológicos que contribuem para a intensificação destas depressões são diversos (A. Fink et al., 2009; A. SEMPLE, 2003), tendo sido destacada a influência de uma corrente de jacto anormalmente rápida na troposfera superior na formação de algumas das tempestades de vento com consequências mais catastróficas nas últimas décadas, na Europa (U. ULBRICH et al., 2001; A. FINk et al., 2009).

Segundo o Centre for Research on the Epidemiology of Disasters (CRED) as tempestades de vento (windstorms) representam cerca de $23 \%$ do total dos desastres naturais na Europa entre 2000 e 2009, sendo só ultrapassadas na categoria de desastres naturais, em peso relativo e número absoluto, pelas inundações (39\%). Os anos a seguir a 2000 viram, segundo a mesma fonte de dados, registar um incremento brutal no número de tempestades em relação às décadas anteriores (fig.1). Aliás, de acordo com o 4th Assessment Report do Intergovernamental Panel on Climate Change (IPCC, 2007) as tempestades têm vindo a aumentar de intensidade desde os anos 60 em ambos os hemisférios. A pergunta que se coloca é a seguinte: como enfrentar os problemas decorrentes da destruição provocados por estes eventos extremos e de que formas nos podemos proteger deles de modo a minimizar os impactes provocados?

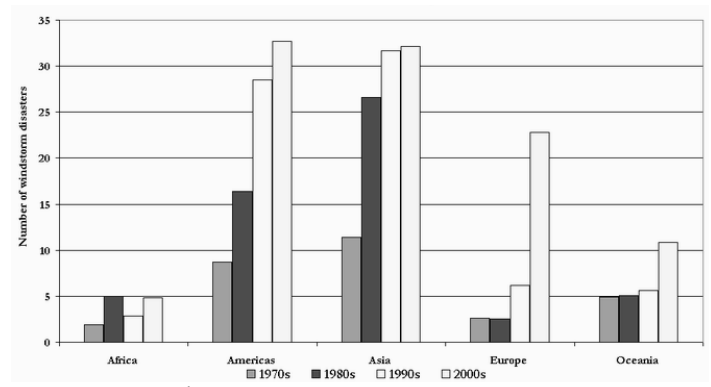

Fig. 1 - Tendências globais de desastres provocados pelas tempestades de vento desde os anos 70 do século XX, com especial destaque para a Europa. Fonte: EM-DAT: The OFDA/ CRED International Disaster Database - www.emdat.net Université Catholique de Louvain - Brussels - Belgium.

Na madrugada de 23 de Dezembro de 2009 a região Oeste (Estremadura e Ribatejo ocidental) foi atingida por uma tempestade particularmente intensa no litoral entre Ribamar e a Lagoa de óbidos. Os ventos muito fortes deixaram um rasto de destruição sobretudo nos concelhos de Torres Vedras, Mafra, Sintra, Cascais, Oeiras, etc. (só para mencionar os que tiveram mais de três dezenas de pedidos de auxílio), com destaque para os efeitos danosos nas estufas de horticultura e fruticultura, actividades que assumem uma posição relevante no contexto económico regional.

As primeiras notícias nos jornais, do dia seguinte ao da tempestade, davam conta de várias famílias desalojadas no Bombarral e no Cadaval, depois das suas habitações terem ficado com os telhados destruídos. Várias estradas municipais estiveram interrompidas pela queda de árvores e ramos, sendo o caso tão preocupante e mediatizado que o próprio ministro da Administração Interna recomendou, publicamente, que os cidadãos se mantivessem em casa durante este período de mau tempo. No início da noite de 24 de Dezembro mais de 40 mil pessoas estavam ainda sem energia eléctrica como consequência da queda de 22 torres de alta tensão de grande dimensão. Numa estimativa inicial (anunciada nos jornais), registaramse perdas de 250 hectares em estufas, 350 hectares de pinhal e 150 de eucaliptal e 53 milhões de euros de prejuízo apenas no concelho de Torres Vedras.

Neste artigo apresentam-se as causas meteorológicas desta tempestade bem como os impactos nas estruturas e populações afectadas, apontando-se, na conclusão, caminhos futuros de investigação.

\section{Dados e metodologia}

$\mathrm{Na}$ caracterização da situação meteorológica em que se desenvolveu a tempestade e na análise dos impactos associados foram utilizados diferentes tipos de informação.

a)Cartas sinópticas publicadas pelo Meterological Office do Reino Unido e cartas sinópticas do Deutscher Wetterdienst Offenbach (Alemanha), disponíveis no portal http://www2.wetter3.de/;

b)Dados de reanálises, úteis para a reconstrução de campos de pressão ao nível do mar e de geopotencial (diferentes níveis troposféricos). Foram usados dados das reanálises ERAInterim e do National Center for Environmental Prediction (NCEP). As reanálises ERA-Interim são disponibilizadas pelo European Centre for MediumRange Weather Forecasts e estão acessíveis com uma resolução de $1,5^{\circ}$ latitude $\times 1,5^{\circ}$ longitude para o período entre 1989 e a actualidade. São disponibilizadas em http://data.ecmwf.int/ data; As reanálises do NCEP, serviram também para elaborar pseudo-sondagens aerológicas e foram recolhidas no sítio http://nomad3.ncep. noaa.gov/. Estão disponíveis com uma resolução de $2,5^{\circ}$ latitude $\times 2,5^{\circ}$ longitude, para o período entre 1948 e a actualidade. No tratamento destes dados de reanálises (ERA-Interim e NCEP) utilizou-se o software GrADS 2.0; 
c)Imagens de satélite Meteosat, recolhidas no sítio www.eumestad.de e imagens de satélite Modis, difundidas pela Dundee Satellite Receiving Station (www.sat.dundee.ac.uk/);

d)Dados de estações meteorológicas. Foram analisados dados das estações com valores das intensidade máximas horárias e direcção do vento, disponibilizados pelo Sistema Nacional de Informação de Recursos Hídricos (SNIRH www.snirh.pt/). Foram igualmente analisados dados de pressão atmosférica da estação de Cabo Carvoeiro (disponíveis de 3 em 3 horas), recolhidos no sítio National Climatic Data Center (www.ncdc.noaa.gov);

e)Os dados utilizados na análise dos impactes do vento na área de estudo foram cedidos pelos Comandos Distritais de Operações de Socorro (CDOS, Autoridade Nacional de Protecção Civil) de Lisboa, Santarém e Leiria, e referemse às operações de auxílio dos dias 23 e 24 de Dezembro de 2009. A base de dados permite uma análise fina das ocorrências, já que contêm as freguesias e coordenadas geográficas dos locais afectados, bem como o tipo de ocorrência. Toda a informação não relevante para este estudo foi retirada e só foi utilizada aquela claramente relacionada com o evento estudado. A natureza das ocorrências consideradas abrangeu: a) na categoria de "Infra-Estruturas e Vias de Comunicação - Queda Árvore” (código da natureza da ocorrência - 3100); Inundação (código 3500); Desentupimento/Tamponamento (código 3600); Dano / Queda Cabos Eléctricos (código 3700); Dano/Queda Estruturas" (código 3800). b) na categoria "Serviços - Limpeza de Via” - Conservação (sinalização de Buraco)" (código 7200).

Alguns dos apuramentos finais encontram-se subestimados na medida em que, quando as quedas reportadas não continham nenhuma descrição pormenorizada sobre a natureza da queda (por exemplo o campo de descrição "NULL"), a ocorrência não foi considerada, apesar de se tratar por exemplo de queda (possivelmente de árvore) não descrita. Por outro lado, algumas ocorrências isoladas relatam várias quedas de árvores, pelo que o valor reportado não deverá corresponder ao número de árvores caídas, mas sim a pedidos de auxílio relacionadas com quedas de árvores. Alguns pedidos de auxílio também se referem a quedas de ramos, com danos materiais, aumentando a incerteza nos apuramentos finais. Avalia-se a subestimação acima dos $30 \%$, o que só poderá ser comprovado em estudos posteriores quando se analisarem as descrições pormenorizadas de cada ocorrência.

A queda de estruturas engloba uma grande diversidade de objectos (telhados, chaminés, painéis publicitários, antenas, toldos, andaimes, etc.). A informação é, em todo o caso, suficientemente detalhada para, em estudos posteriores, se poder avaliar mais pormenorizadamente os impactes sócio-económicos das tempestades de vento.

Como a maior parte das ocorrências durante este evento estão relacionadas com o vento e em menor número com a chuva, agruparam-se as categorias de acordo com o critério de associação da ocorrência com um ou o outro elemento (Quadro I). Como se pode observar no quadro, a maior parte das ocorrências a que as equipas de bombeiros atenderam foram reportadas no Distrito de Lisboa e referiram-se a quedas de árvores e cabos eléctricos (45\%). Nos três distritos estudados as ocorrências relacionadas com o vento forte (quedas de árvores, cabos eléctricos e estruturas) totalizaram $89 \%$ das chamadas durante os 2 dias analisados, sendo os restantes $11 \%$ atribuídos a ocorrências relacionadas com a chuva (inundações e desentupimentos). No quadro são apresentados os totais de chamadas relacionadas com quedas de árvores e cabos eléctricos por serem objectos que caem directamente sobre pessoas e bens, mas que não sofrem geralmente arrasto. As restantes estruturas, na presença de ventos fortes, são normalmente arrastadas ou projectadas a média e longa distância, podendo colidir com pessoas num raio maior.

Depois de disponibilizada toda a informação, esta foi inserida numa geo-database (ArcGIS), onde se procedeu ao seu tratamento estatístico e cartográfico. Os principais problemas encontrados na transposição da informação para a base de dados da "Carta Administrativa Oficial de Portugal” (CAOP 2009.0), que

QUADRo I - Ocorrências reportadas aos CDOS das 0:00 h de 23 às 18:00 h de 24 de Dezembro de 2009.

\begin{tabular}{|c|c|c|c|c|c|c|c|c|}
\hline & Lisboa & $\%$ & Santarém & $\%$ & Leiria & $\%$ & Total & $\%$ \\
\hline Inundações /Infiltrações & 58 & 8 & 5 & 1 & 4 & 1 & 67 & 10 \\
\hline Desentupimentos /Tamponamentos & 15 & 2 & 1 & 0,1 & 1 & 0,1 & 17 & 2 \\
\hline Quedas (arvores e cabos eléctricos) & 312 & 45 & 62 & 9 & 101 & 15 & 475 & 69 \\
\hline Quedas de estruturas & 78 & 11 & 26 & 4 & 28 & 4 & 129 & 19 \\
\hline Total & 463 & 67 & 94 & 14 & 134 & 19 & 691 & 100 \\
\hline
\end{tabular}


tem os limites das freguesias, prenderam-se com o facto de alguns dos campos não terem a mesma composição alfanumérica (nomes das unidades ligeiramente diferentes), o que obriga à transposição manual dos valores finais das ocorrências. Torna-se assim necessário que as bases de dados dos CDOS respeitem a cartografia operacional oficial disponibilizada pelo IGP para agilizar os apuramentos. Por outro lado, como foi já referido por S. Oliveira e A. LOPES (2007) e A. LoPEs et al. (2008), existem normalmente problemas relacionados com a elaboração das bases de dados pelos serviços de bombeiros e protecção civil que são nomeadamente: a) a hora registada de cada ocorrência corresponde à hora de recepção do telefonema pelos bombeiros e não à hora em que ocorrem os possíveis danos, havendo normalmente um desfasamento de tempo que não é possível identificar; b) as ocorrências registadas na base de dados referem-se normalmente a incidentes que causaram danos pessoais ou colectivos/patrimoniais de valor e muitos deles ficam por reportar na base de dados que é actualizada durante o evento e não posteriormente. No presente caso, devido à excepcionalidade do evento, os danos começaram a ser reportados às primeiras horas da madrugada, constituindo um caso atípico. A experiência de outros trabalhos (A. Lopes et al., 2008) mostra que, normalmente, quando as tempestades ocorrem durante a noite e a madrugada as chamadas de auxílio começam, geralmente, nas primeiras horas da manhã, quando os cidadãos se levantam e verificam que sofreram com o temporal. No presente caso, a forte intensidade do vento acordou os cidadãos que começaram a pedir auxílio desde a primeira hora da tempestade.

\section{Causas meteorológicas: um evento de ciclogénese rápida}

Pela violência dos ventos registados ao nível da superfície, a depressão associada a este evento pode ser mais adequadamente designada como uma tempestade extratropical e o interesse em estudar este episódio notável não decorre apenas das suas consequências muito gravosas, mas também por se ter tratado de uma situação meteorológica muito particular, evidenciando diversos indícios de ter correspondido a uma evolução do tipo ciclogénese rápida (A. SEMPLE, 2003; K. BrownING, 2004). A depressão frontal responsável por este episódio de ventos muito fortes à superfície, caracterizou-se pela rápida passagem dos estádios evolutivos do seu ciclo de vida, adquirindo uma estrutura típica reveladora da maturidade do sistema ciclónico em apenas cerca de 12-15 horas, acompanhando um aprofundamento barométrico que se processou a uma taxa muito elevada, e que terá ultrapassado os $4 \mathrm{mb} /$ hora no período de maior intensificação. Pela sua mais curta duração, a evolução desta depressão não terá constituído um caso de ciclogénese dita explosiva, o que implicaria uma intensificação superior ou igual a $1 \mathrm{mb} / \mathrm{h}$ durante $24 \mathrm{~h}$ (aplicando a definição proposta por F. SANDERS e J. GYAKUM, 1980), mas tratou-se de um sistema depressionário notável, que se materializou no rápido desenvolvimento de um vórtice ciclónico, em estádio de maturidade, dominado por uma compacta massa nebulosa em espiral rodeando um núcleo desprovido de nuvens, e em cujas proximidades ocorreram ventos fortíssimos, que também se fizeram sentir ao nível da superfície.

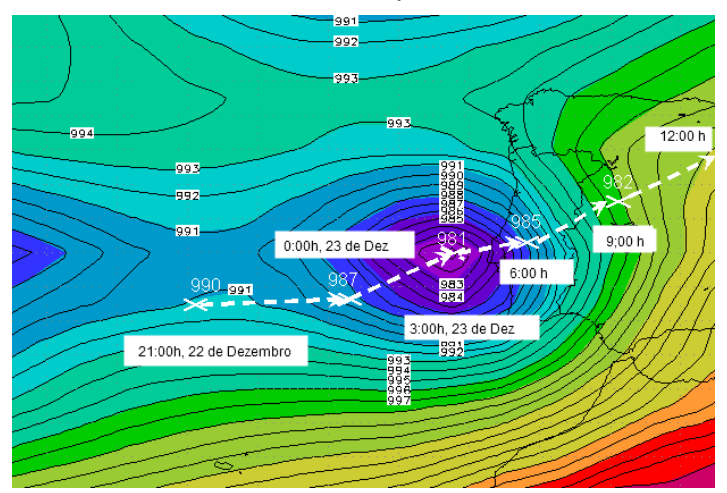

Fig. 2 - Trajectória da tempestade extratropical de 23 de Dezembro de 2009. Os valores indicados correspondem aos mínimos de pressão (em mb) nos campos de pressão ao nível do mar das reanálises ERA-Interim, entre as 21:00 de 22/12/09 e $12: 00$ de 23/12/09, ilustrando o movimento do centro de baixas pressões em intervalos de tempo de 3 horas. Fonte: ECMWF.

O núcleo de baixa pressão que esteve na origem deste evento formou-se no início da tarde de 22 de Dezembro de 2009, tendo-se intensificado nas últimas horas desse dia. As cartas sinópticas de superfície consultadas a partir do boletim meteorológico alemão, disponíveis de 3 em 3 horas (não apresentadas neste trabalho), sugerem que o começo da individualização deste centro de baixas pressões ocorreu entre a 12:00 h e as 15:00 h UTC do dia 22 de Dezembro. Apresentam-se dois extractos de cartas sinópticas de superfície ilustrativos da posição do núcleo depressionário pouco antes deste atingir a costa da Estremadura portuguesa (fig. 3a). A aproximação e a passagem da depressão pela região Oeste terão ocorrido entre as 0:00 h e as 06:00 h do dia 23, podendo deduzirse o seu movimento e trajectória a partir das cartas, comparando a posição do núcleo de baixa pressão identificado pelos valores mínimos de $985 \mathrm{mb}$ (às 0:00 h) e $979 \mathrm{mb}$ às 6:00 h. Foi entre os dois momentos retratados que a depressão atingiu o seu estádio de maturidade, altura que se atingiu o máximo cavamento barométrico (fig. 3b) e que os sistemas nebulosos associados revelaram o seu maior desenvolvimento.

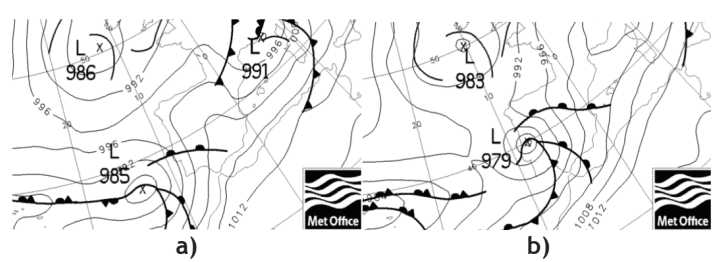

Fig. 3 - Extractos de cartas sinópticas da superfície (Met Office, Reino Unido) ilustrativos da área de Portugal Continental, às 00:00 h (a) e às 06:00 h de 23.12.2009 (b).

Fonte: http://www.wetter3.de/Archiv/archiv_ukmet.html. 
Como também se pode observar na figura 3, este centro de baixas pressões progrediu de Sudoeste para Nordeste e o seu núcleo atingiu a costa ocidental portuguesa precisamente na área do litoral da Estremadura, sensivelmente próximo do Cabo Carvoeiro. Durante a manhã do dia 23, esta depressão prosseguiu a sua trajectória para Nordeste, deixando o território português, mas foi no período que decorreu entre os momentos retratados que o centro de baixa pressão registou uma excepcional actividade, que se manifestou sobretudo pela intensidade dos ventos junto à superfície, como se verá adiante.

A formação e evolução desta depressão processaram-se em condições de circulação atmosférica zonal noAtlântico Norte Oriental, devendo notar-se a presença de uma corrente zonal rápida às latitudes da margem ocidental da Península Ibérica, como se ilustra na figura 4. Nos campos dos geopotenciais representados identifica-se uma corrente rápida de sudoeste nos níveis médios e altos da troposfera que terá conduzido a trajectória da depressão aos níveis inferiores. Na troposfera superior existe uma zona de divergência na corrente de jacto sobre o Atlântico a sudoeste da Península, abrangendo o sector onde se formou a tempestade. Este é um dos factores que podem contribuir para a ciclogénese e o desenvolvimento de intensos ciclones extratropicais (L. UcCelLINI, 1990; A. Fink et al., 2009). Numa investigação anterior (M. Fragoso e A. LoPES, 2009), foi determinado que as situações depressionárias frontais associadas a correntes zonais de Oeste muito rápidas (semelhantes às que se verificaram na tempestade de 23 de Dezembro de 2009) estiveram na origem de 30\% dos casos de uma amostra de episódios de ventos fortes registados na cidade de Lisboa $(128$, inventariados no período 1990-2006).

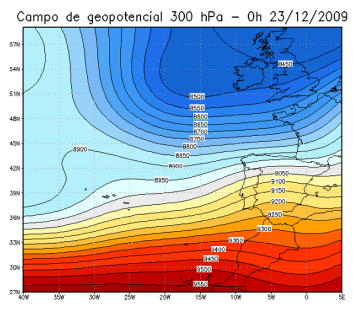

a)

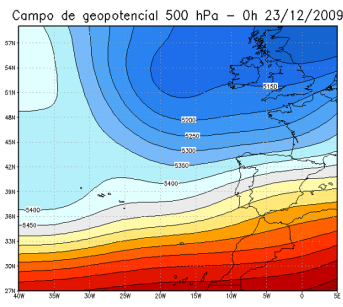

b)
Fig. 4 - Campos dos geopotenciais dos 300 e $500 \mathrm{mb}$, às $0: 00 \mathrm{~h}$ UTC de 23 de Dezembro de 2009 (isoípsas em metros). Fonte: www.data.ecmwf.int/data/.

$\mathrm{Na}$ ausência de sondagens aerológicas ilustrativas da estrutura desta depressão (na estação de radiossondagem mais próxima, em Lisboa, não são feitas sondagens às 0:00 h UTC), pode procurar-se uma aproximação da reconstituição do perfil vertical da atmosfera na área do centro de baixas pressões, recorrendo à elaboração de uma pseudo-sondagem, construída com base na utilização de dados de reanálises. Assim, foi feita uma pseudo-sondagem utilizando dados de pressão atmosférica, temperatura do ar, humidade relativa, direcção e velocidade do vento, relativos ao ponto de rede definido pela latitude de $39^{\circ} \mathrm{N}$ e pela longitude de $10^{\circ} \mathrm{W}$, extraindo a informação descrita correspondente às 0:00 h UTC. 0 núcleo central do sistema depressionário encontrava-se, nesse momento, muito próximo do local mencionado, pelo que a pseudo-sondagem realizada (fig. 5) permite obter algumas indicações sobre a estrutura vertical da coluna troposférica cerca de 3 a 4 horas antes da tempestade fustigar a região Oeste.

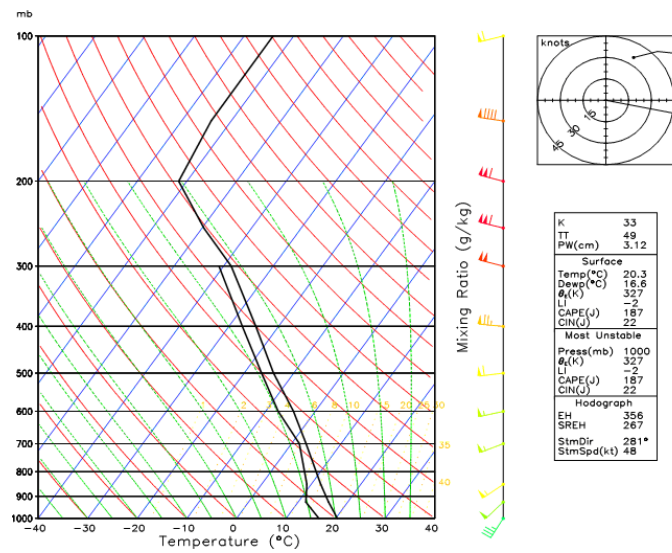

Fig. 5- Pseudo-sondagem elaborada no ponto de rede com coordenadas $39^{\circ} \mathrm{N}$ e $10^{\circ} \mathrm{W}$, às $0: 00 \mathrm{~h}$ de $23 / 12 / 2009$, utilizando dados atmosféricos das reanálises NCEP-1. Os triângulos nos vectores de vento representam 25 nós, os segmentos maiores 10 nós, e os menores 5 nós. Fonte: www.ncep.noaa.gov.

Observando a fig. 5, verifica-se uma estrutura marcada por condições de instabilidade convectiva, sendo de destacar dois aspectos: a) a presença de ar frio nos níveis médios e elevados, sobrepondo-se a uma massa de ar quente $\left(20,3^{\circ} \mathrm{C}\right.$ à superfície) e muito húmida $(3,1 \mathrm{~cm}$ de água precipitável) na troposfera inferior. Estas condições termodinâmicas eram, às 0:00 h do dia 23 manifestamente favoráveis à convecção, como o demonstram os valores dos índices CAPE (+187 Joules/Kg), Li $\left(-2^{\circ} \mathrm{C}\right)$ e Total Totals (49); b) existência de uma corrente de jacto na troposfera superior, com vento de Oeste soprando com velocidades de 50-60 nós acima dos $300 \mathrm{mb}$. Nas horas que se seguiram ao momento retratado nesta pseudosondagem, verificou-se um reforço na intensificação do cavamento da baixa pressão à superfície, bem como um extraordinário e rápido desenvolvimento dos sistemas nebulosos associados à depressão.

O cavamento rápido do centro de baixas pressões pode ser confirmado pela queda súbita de pressão atmosférica na estação de Cabo Carvoeiro (fig. 6), tendo em atenção que o núcleo da depressão terá passado relativamente próximo do local. Entre as 18:00 h do dia 22 e as 3:00 $\mathrm{h}$ do dia 23 , a pressão atmosférica baixou neste local $20,1 \mathrm{mb}$, devendo destacar-se que, nas últimas 3 horas desse período, a queda de pressão foi de $12,1 \mathrm{mb}$, representando uma taxa de decréscimo superior a $4 \mathrm{mb}$ / hora. Segundo um relatório publicado pelo I.M. sobre 
este episódio de vento forte (P. Pinto e A. Silva, 2010), o valor mínimo de pressão atmosférica ao nível do mar no Cabo Carvoeiro foi de $969,4 \mathrm{mb}$, pelas 4:20 h UTC.

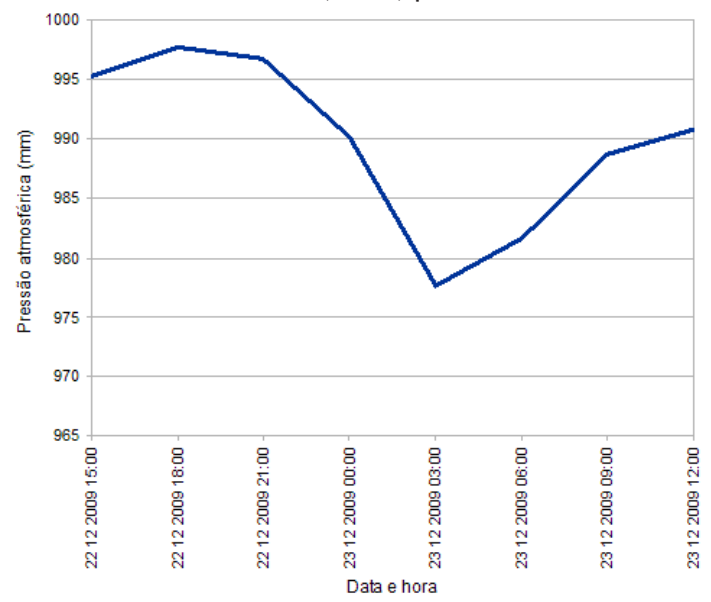

Fig. 6 - Variação da pressão atmosférica medida na estação de Cabo Carvoeiro (alt.: $34 \mathrm{~m}$ ) entre as 15:00 h do dia 22/12/2009 e as 12:00h do dia 23/12/2009 (valores de 3 em 3 horas). Fonte: NCDC.

A observação de imagens do satélite Meteosat permitiu confirmar que esta depressão frontal se caracterizou pela passagem muito rápida das diferentes fases do seu ciclo vida, tendo adquirido características típicas de um estádio de maturidade (fase IV no modelo conceptual de Shapiro e Keyser, 1990, citados por A. Semple, 2003) por volta das 03:00h UTC, cerca de 15 horas após a formação das primeiras massas nebulosas, o que corresponde a uma duração comparável à que tem sido descrita noutros casos notáveis de ciclogéneses rápidas (A. SEMPLE, 2003). Apesar de, por limitações de espaço, não ser possível resumir aqui toda essa sequência, seleccionaram-se duas imagens Meteosat (figura 7a e b) e uma imagem proveniente do sensor MODIS (satélite Aqua, fig. 7c), respeitante a um dos canais Infravermelho, e que é bem ilustrativa do extraordinário desenvolvimento dos sistemas nebulosos associado a esta depressão.

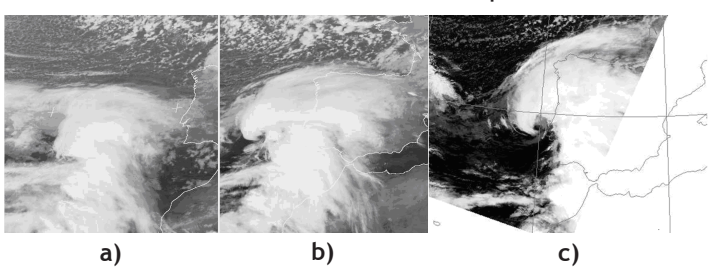

Fig. 7 - Aspectos da evolução do sistema nebuloso da depressão que atingiu o Oeste em 23 de Dezembro de 2009: imagens do satélite Meteosat, canal 9/infravermelho térmico $(9,8-11,8$ $\mu \mathrm{m})$, às 18:00h UTC do dia 22 e às 0:00h UTC do dia 23 (b); c - Extracto de imagem "quicklook", captada às 03:11:52h UTC do dia 23, do canal 31/Infra-Vermelho Térmico do sensor MODIS $(10,780-11,280 \mu \mathrm{m})$. Fonte: NERC Satellite Receiving Station, Dundee University, Scotland (ww.sat.dundee.ac.uk)..

O traçado da órbita do satélite MODIS em que esta imagem foi obtida não permitiu a captação da totalidade da massa nebulosa da depressão, designadamente da nebulosidade associada à frente quente do sistema frontal e de parte da frente fria. No entanto, o instante da passagem sobre a área do território de Portugal Continental coincidiu, aproximadamente, com o período de maior actividade da tempestade, e são bem visíveis alguns aspectos reveladores da intensidade da depressão. 0 núcleo central, quase desprovido de nuvens, é rodeado por uma extensa e muito compacta massa de nuvens de grande desenvolvimento vertical (cumulonimbus), envolvendo o vórtice por uma massa de nuvens com uma configuração em espiral. Igualmente visível é o turbilhão nebuloso interrompido a sul do núcleo central por uma estreita faixa (ou língua) desprovida de nuvens, sugerindo a presença de uma intrusão de ar seco, descendo desde os níveis mais elevados da troposfera. Por outro lado, o sector ocidental da depressão apresenta uma massa de nuvens de topo muito frio, resultado de convecção forte. A «cabeça» do sistema, traduzido do termo anglosaxónico cloud-head, em cuja extremidade se identifica um prolongamento nebuloso em forma de gancho, quase contorna o núcleo da depressão. Segundo K. BRownING (2004), nas depressões extratropicais de evolução rápida que evidenciam estruturas nebulosas de mesoescala do tipo das que aqui foram descritas, produzem-se geralmente ventos muito violentos à superfície, por vezes associados à formação de correntes de jacto na média e baixa troposfera (low level jets ou sting jets/jet streaks).

\section{A Intensidade do vento junto do núcleo depressionário}

A figura 8 mostra as intensidades máximas horárias da velocidade do vento no dia 23 de Dezembro de 2009. As estações escolhidas foram as da rede de monitorização do SNIRH com dados disponíveis. As estações encontramse ordenadas na legenda de norte para sul, para melhor se perceber os momentos em que as máximas intensidades foram observadas. No conjunto destes locais, a primeira estação meteorológica a registar o valor máximo $(19,1 \mathrm{~m} / \mathrm{s})$ foi a de "Malveira da Serra", no sul da região, no sopé da serra de Sintra, cerca das 2:00 h da madrugada, altura a partir da qual se começaram a registar os primeiro pedidos de auxilio. Duas horas mais tarde, (4:00 h) a estação de Cheleiros, a norte da Serra, registou o seu máximo horário $(19,2 \mathrm{~m} / \mathrm{s})$ e só uma hora mais tarde as estações localizadas mais a norte registam o máximo de intensidade (Orjariça - 22,4 m/s; Pragança - $31 \mathrm{~m} / \mathrm{s}$ ). A estação meteorológica de "Barragem de Óbidos" regista o seu valor máximo $(25,3 \mathrm{~m} / \mathrm{s})$ uma hora depois das anteriores $(6: 00 \mathrm{~h})$. A estação de Turquel, fora da influência do centro mais activo depressionário apenas regista valores ligeiramente superiores a $11 \mathrm{~m} / \mathrm{s}$.

Um pico secundário, mas menos intenso, ocorreu ao fim da tarde, a partir das 18:00 h com valores registados entre os 8 e os $15 \mathrm{~m} / \mathrm{s}$. Esta segunda vaga de intensidade deveu-se à aproximação de uma nova 
depressão frontal, não se relacionando directamente com a tempestade em estudo. No entanto, algumas das ocorrências da base de dados estão relacionadas com a passagem desta segunda depressão, tendo sido por isso sido contabilizadas no evento.

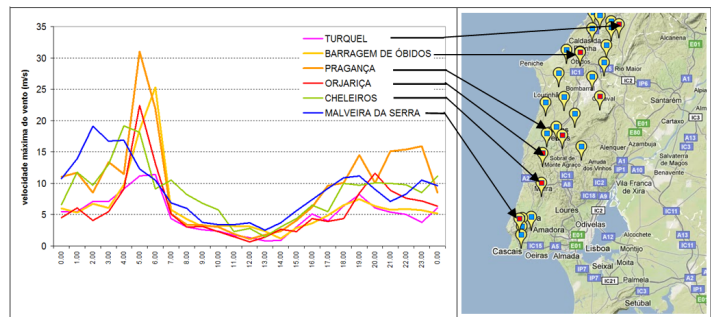

Fig. 8 - Velocidades máximas horárias do vento registadas em estações meteorológicas da bacia hidrográfica das "Ribeiras do Oeste". Fonte: SNIRH (http://snirh.pt/).

O evento foi ainda marcado pela variação brusca da direcção do vento num curto espaço de tempo, passando da direcção de SE para Oeste em apenas três horas (fig.9). No exemplo da estação de Pragança (fig. 9c), onde se verificou a intensidade máxima horária, a passagem rápida do núcleo depressionário impôs uma mudança nos rumos em apenas duas horas.

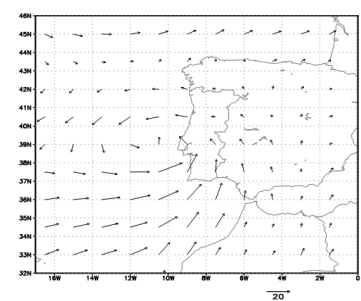

a) $3: 00 \mathrm{~h}$

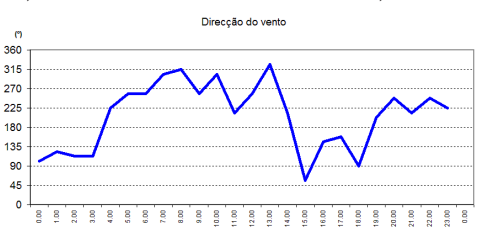

c) $3: 00 \mathrm{~h}$

Fig. 9 - Direcções do vento a $10 \mathrm{~m}$ às 3:00 h (a) e 6:00h (b). Fonte: Reanalysis ERA-Interim. Em c) é apresentada a direcção do vento na estação meteorológica de Pragança. Fonte: SNIRH (http://snirh.pt/).

\section{Consequências e impactes}

Como já foi anteriormente referido, a maior parte das ocorrências (cerca de 89 \%) estiveram relacionadas com o vento muito forte que se fez sentir e que ocasionou, sobretudo, a queda de árvores, cabos eléctricos e outras estruturas (fig. 10).

De acordo com as informações recolhidas e divulgadas pela agência noticiosa LUSA, os concelhos do Oeste mais afectados pela tempestade foram os de Alenquer, Azambuja, Cadaval, Lourinhã, Mafra, Sobral de Monte Agraço e Torres Vedras, onde o mau tempo causou prejuízos na ordem dos 63 milhões de euros, segundo as estimativas dos municípios atingidos. No entanto, à data

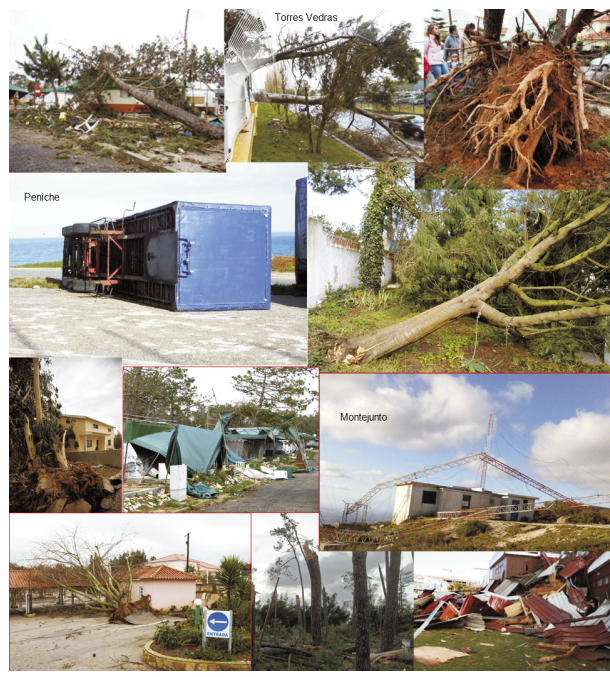

Fig. 10 - Fotografias disponibilizadas online pelos órgão de comunicação social mostrado os efeitos devastadores da tempestade.

da elaboração deste artigo, ainda não estão divulgados publicamente os prejuízos totais. Ao contrário de outros países que divulgam os montantes pagos pelas companhias de seguros com os estragos causados pelos fenómenos climáticos extremos ( $M$. KlaWA e U. UlBRICH, 2003; J. Pinto et al., 2007), o que permite criar modelos estatísticos mais precisos que ajudam as sociedades a calcular o risco com grande exactidão (D. MARTEAU et al., 2004), em Portugal ainda não foram criados os canais de comunicação necessários à prevenção do risco económico, basicamente por falta de divulgação dos valores indemnizatórios.

Na fig. 11 ilustra-se a variação temporal das operações de socorro nos distritos analisados ao longo do dia 23 de Dezembro de 2009, podendo observar-se que as chamadas de auxílio atingiram o seu maior número logo na sequência dos ventos mais violentos, a partir das 5:00h da madrugada. O número de operações foi diminuindo ao longo da manhã mas verificou-se, no entanto, um certo recrudescimento durante a tarde, quando uma nova depressão se aproximou do território português, possivelmente causando novos efeitos destruidores ou agravando os decorrentes da tempestade anterior.

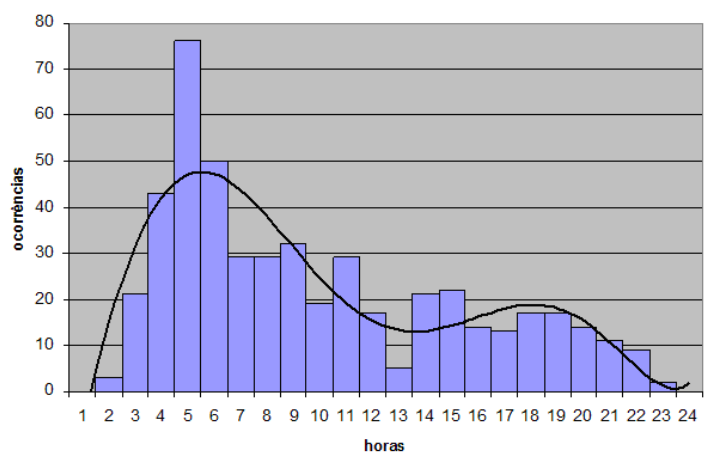

Fig. 11 - Ocorrências horárias reportadas pelos CDOS de Lisboa, Santarém e Leiria referentes às operacões de auxílio dos dias 23 e 24 de Dezembro de 2009. 
A trajectória do centro da depressão, determinada a partir das reanálises NCEP (fig. 2), teve uma orientação oés-sudoeste/és-nordeste, o que indicia a penetração em terra do centro mais activo da baixa pressão a pouco mais de $40 \mathrm{~km}$ a norte da cidade de Lisboa, progredindo depois para ENE, atingindo mais tarde a parte norte da região. Esta trajectória é consistente com os ventos observados nas estações meteorológicas (fig. 8): o pico mais elevado de vento máximo horário ocorreu primeiramente numa estação a sul da Serra de Sintra (Malveira da Serra - 19,1 $\mathrm{m} / \mathrm{s}$ ), e só mais tarde, depois das 5:00h, as estações mais a norte (Pragança e Barragem de Óbidos) registaram os valores mais elevados durante o evento (31 e 25,3 $\mathrm{m} / \mathrm{s}$, respectivamente). O segundo pico de ocorrências no final da tarde deverá ter estado relacionado com o novo aumento da velocidade do vento registado a partir das 16:00h. A resposta das entidades envolvidas nas acções de socorro durante todo o dia 23 de Dezembro de 2009 correspondeu, portanto, aos picos máximos de intensidade do vento. A cidade de Lisboa foi relativamente pouco atingida (fig.12), o que se compreende em face da trajectória da tempestade. A oeste, nos concelhos de Cascais e Oeiras, as ocorrências foram essencialmente devidas à ocorrência de pluviosidade intensa. Para norte do conjunto de concelhos do sul da península de Lisboa as ocorrências deveram-se sobretudo à força do vento. A linha definida anteriormente como a provável trajectória da parte central e mais intensa da depressão, a posição do núcleo ciclónico nas imagens de satélite e o padrão das ocorrências descrito anteriormente, leva-nos a concluir que o que o diâmetro do centro de maior actividade destruidora da tempestade não terá sido muito superior a 80 km (fig.12a).

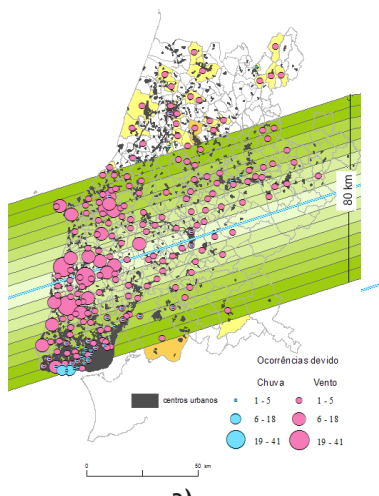

a)

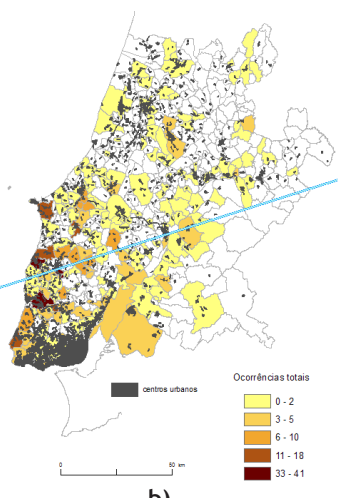

b)
Fig. 12 - Ocorrências devidas ao vento forte e à chuva a) e totais b) nos dias 23 e 24 de Dezembro de 2010. A linha diagonal mostra a trajectória aproximada do centro da depressão determinada a partir das reanálises NCEP. O espaço delimitado a verde em a) representa um buffer de $40 \mathrm{~km}$ para cada lado dessa linha, correspondente à área de maior potencial destruidor da tempestade.

A correlação entre a maior parte das ocorrências e a localização dos centros urbanos (fig. 12b) confirma que são as áreas mais habitadas, normalmente, as primeiras a ser socorridas, servindo esta informação para que, no futuro, possa ser construído um modelo ainda mais eficaz de socorro, sabendo quais são as áreas mais vulneráveis e os trajectos mais adequadas para as operações de auxílio. A informação apresentada poderá portanto servir de ponto de partida para a elaboração de uma cartografia de risco, baseada em critérios de vulnerabilidade e de susceptibilidade e tendo em conta as melhores acessibilidades para o socorro às populações e definir critérios de prioridades.

\section{Conclusão}

Neste trabalho demonstrou-se que a tempestade extratropical que afectou sobretudo a região Oeste de Portugal no dia 23 de Dezembro de 2009 teve como causa meteorológica uma ciclogénese rápida, que se desenvolveu num contexto de circulação zonal veloz de Oeste. A situação responsável por ventos muito fortes à superfície, com rajadas por vezes superiores a $40 \mathrm{~m} / \mathrm{s}$ (142 km/h na estação de Dois Portos) e intensidades médias horárias na ordem dos $30 \mathrm{~m} / \mathrm{s}(108 \mathrm{~km} / \mathrm{h})$, caracterizou-se pela evolução rápida de um sistema ciclónico que, em apenas 12 a 15 horas, atingiu o seu estádio de maturidade, acompanhando um cavamento barométrico que chegou a ser superior a $4 \mathrm{mb} /$ hora, entre 0:00h e as 3:00h UTC.

As consequências dos ventos fortes ocorreram em maior número junto ao litoral, numa faixa com orientação definida pela linha de trajectória do centro da depressão. 0 maior número de ocorrências foi registado no distrito de Lisboa (67\%), apesar da cidade praticamente não ter sido afectada. Foram sobretudo a quedas de árvores e cabos eléctricos (69 $\%$ nos 3 distritos) que dominaram as atenções nesse dia. No entanto, pelo valor económico, muitas outras estruturas (sobretudo estufas e poste de alta tensão) foram literalmente arrancadas do chão, deixando muitas dezenas de famílias sem energia e com as culturas de estufa totalmente perdidas.

Devido ao grande número de árvores caídas em meio urbano (mais de 3 centenas), conforme a base de dados da ANPC, insiste-se na ideia de que é urgente fazer um inventário das árvores, especialmente em meio urbano, onde se inclua, entre outras informações, a idade e o estado fitossanitário da floresta urbana, de modo a se saber exactamente quais as espécies mais adaptadas aos solos e ambientes urbanos e as que melhor resistem aos fenómenos extremos. Um mapa de vulnerabilidades deverá ser um dos objectivos deste estudo, já iniciado em Lisboa (A. Lopes et al., 2008). Só depois desse levantamento efectuado e sabendo-se as frequências de ocorrência das tempestades na região ( $M$. Fragoso e A. LOPES, 2009) se poderá proceder à cartografia de risco de quedas (especialmente de árvores). 
O SIG construído para este estudo de caso, poderá igualmente conduzir a outros estudos importantes, nomeadamente a determinação das melhores trajectos no auxílio às populações afectadas.

\section{Agradecimentos}

Este trabalho foi elaborado no âmbito do projecto "DISASTER - Desastres naturais de origem hidrogeomorfológica em Portugal: base de dados SIG para apoio à decisão no ordenamento do território e planeamento de emergência” (PTDC/CS-GEO/103231/2008).

\section{Referências bibliográficas:}

BRownING, K. (2004) - "The sting at the end of the tail: damaging winds associated with extratropical cyclones", Quarterly Journal of the Royal Meteorological Society, 130, p. 385-399.

Fink, A., Brücher; T., Ermert; V., Krüger; A., Pinto, J. (2009) - "The European storm Kyrill in January 2007: synoptic evolution, meteorological impacts and some considerations with respect to climate change", Natural Hazards and Earth Systems Sciences, 9, p. 405-423.

Fragoso, Marcelo e Lopes, António (2009) - "Large-scale atmospheric circulation and sounding derived parameters associated with windstorm events in Lisbon (Portugal)". In Pribullova and Bičarova (Ed) Proceedings of International Scientific Conference Sustainable Development and Bioclimate. Stará Lesná, Slovakia, 5-8 October, p. 12-13.

IPCC (2007) - The Physical Science Basis. Contribution of Working Group I to the Fourth Assessment Report of the Intergovernmental Panel on Climate Change. In Solomon, S., Qin D. Manning, M., Chen, Z., Marquis, M., Averyt K., Tignor, M. e Miller, H. (Ed). Cambridge University Press, Cambridge, United Kingdom and New York, NY, USA. 996 p.

KlaWA, M. e Ulbrich, U. (2003) - "A model for the estimation of storm losses and the identification of severe winter storms in Germany". Natural Hazards and Earth System Science, 3(6), p. 725-732.

Lopes, António; Oliveira, Sandra, Fragoso, Marcelo, Andrade, José, Pedro, Pedro (2008)- "Wind risk assessment in urban environments: the case of falling trees during windstorm events in Lisbon", In. Střelcová, K. et al. (Ed), Bioclimatology and Natural Hazards, Springer, p. 55-74.
Lopes, António; Oliveira, Sandra; Fragoso, Marcelo (2008) - "Vento Forte e queda de árvores em Lisboa. Avaliação e primeiros resultados", In Alcoforado, M.J. et al. (Ed), Estudos sobre Cidades e Alterações Climáticas. CEG/A.I.G-E., 8, p. 71-91.

Marteau, D; Carle, J.; Fourneaux, S.; Holz, R.; Moreno, M. (2004) - La gestion du risque climatique, Economica/MeteoFrance. $211 \mathrm{p}$.

Oliveira, Sandra e LoPes, António (2007) - “Metodologia de avaliação do risco de queda de árvores devido a ventos fortes na cidade de Lisboa", Actas do VI Congresso da Geografia Portuguesa. FCSH, Lisboa, $21 \mathrm{p}$.

Pinto, J.; Fröhlich, E.; Leckebusch, G.; Ulbrich, U. (2007) - "Changing European storm loss potentials under modified climate conditions according to ensemble simulations of the ECHAM5/MPIOM1 GCM". Natural Hazards and Earth System Science, 7(1), p.165-175.

Pinto, J.; Stefan, Z; Fink, A.H.; Leckebusch, G.C.; Ulbrich, U. (2009) - "Factors contributing to the development of extreme North Atlantic cyclones and their relationship with the NAO", Climate Dynamics, 32, p. 711-737.

Pinto, P., Silva, A. (2010) - "Situação de vento forte no Oeste em 23 de Dezembro de 2009", Disponível: http://www.meteo.pt/resources. www / docs_pontuais/ocorrencias2009/ RelVentoOeste.pdf, 40 p. [Janeiro de 2010].

Sanders, F.; Gyakum, J.R. (1980) - "Synoptic-Dynamic climatology of the "bomb", Monthly Weather Revue, 108, p. 1589-1606.

Semple, A. T. (2003) - "A review and unification of conceptual models of cyclogenesis", Meteorological Applications, 10, p. 39-59.

UCCELLINI, L. W., Johnson, D.R. (1979) - "The coupling of upper and lower tropospheric jet streaks and implications for the development of severe convective storms", Monthly Weather Revue, 107, p. 682-703.

Ulbrich, U.; Fink, A.H., Klawa, M.; Pinto, J. (2001) - “Three extreme storms over Europe in December 1999", Weather, 56, p. 70-80. 